Teaser Copper radioisotopes are emerging as potent tools for developing unprecedented clinical approaches for cancer treatment by exploiting the intrinsic biological properties of

\title{
The emerging role of copper-64 radiopharmaceuticals as cancer theranostics
}

\section{Alessandra Boschi ${ }^{1}$, Petra Martini ${ }^{1}$, Emilija Janevik-Ivanovska ${ }^{2}$ and Adriano Duatti ${ }^{3}$}

\footnotetext{
${ }^{1}$ Department of Morphology, Surgical and Experimental Medicine, University of Ferrara, 44121 Ferrara, Italy

${ }^{2}$ Faculty of Medical Sciences, University 'Goce Delčev', Štip, Republic of Macedonia

${ }^{3}$ Department of Chemical and Pharmaceutical Sciences, University of Ferrara, 44121 Ferrara, Italy
}

Copper radionuclides are rapidly emerging as potential diagnostic and therapeutic tools in oncology, particularly ${ }^{64} \mathrm{Cu}$-radiopharmaceuticals for targeting neuroendocrine, prostate, and hypoxic tumors. Unexpectedly, experimental results are also revealing the impressive biological behavior of simple $\left[{ }^{64} \mathrm{Cu}^{2+}\right]$ ions. For example, it has been demonstrated that administration of ionic $\left[{ }^{64} \mathrm{Cu}^{2+}\right]$ in physiological solution allows the selective targeting of a variety of malignancies. These remarkable biological properties appear to be crucially linked to the natural role of copper ions in cell proliferation. Here, we review the current status of ${ }^{64} \mathrm{Cu}$-radiopharmaceuticals in molecular imaging and cancer therapy.

\section{Introduction}

Molecular imaging [1-6] is a fascinating concept that has deeply influenced modern diagnostic imaging and therapy. However, its definition is rather vague and does not fully meet the strict requirements of a rigorous scientific concept, resulting in an ongoing lengthy debate. In an attempt to develop a definition that includes its most relevant characteristics, the Society of Nuclear Medicine and Molecular Imaging (SNMMI) proposed the following statement: 'Molecular imaging is the visualization, characterization, and measurement of biological processes at the molecular and cellular levels in humans and other living systems' [6].

Some ambitious interpretation entails that the meaning of the term 'molecular' should be interpreted as the level of spatial resolution that can be attained by methods used for imaging biomolecules in living systems. Only when the same atomic-scale resolution typical of structural chemistry is achieved can the molecular attribute be applied. However, this result is still beyond reach because there is no available imaging technology capable of truly detecting single molecules in living tissues with atomic resolution.

Another interpretation suggests that molecular imaging corresponds to mapping the distribution and activity of molecules in living tissues. This description is linked to the concept of a molecular imaging agent that is defined as a 'probe' used to visualize, characterize, and measure

Corresponding author:
Alessandra Boschi is currently the head of the Radiation Safety and Control Section at the University of Ferrara and a assistant professor of radiochemistry. Her research interests focus mainly on the development of novel chelating systems for radiometals and the application of radionuclide imaging in preclinical studies.

Petra Martini is currently a postdoc at the Legnaro National Laboratories of the INFN. She is also a researcher fellow at the University of Ferrara. She has also worked at TRIUMF Canada's Particle Accelerator Centre. Her main research interests focus on
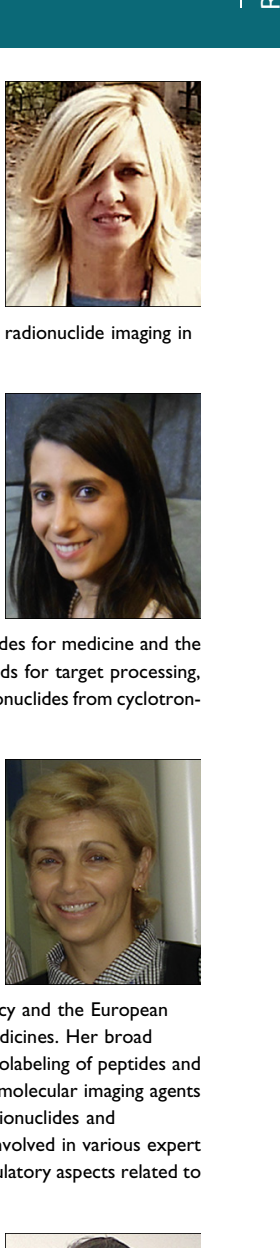

the production of novel radionuclides for medicine and the development of automated methods for target processing separation, and purification of radionuclides from cyclotronirradiated targets.

Emilija Janevik-Ivanovska is currently a professor in pharmaceutical chemistry and technology at the University of Stip. She is also the director of the University Institute for Positron Emission

Tomography in Skopje. She is also expert consultant to the

International Atomic Energy Agency and the European Directorate for the Quality of Medicines. Her broad

research interests range from radiolabeling of peptides and antibodies to the development of molecular imaging agents labeled with positron-emitting radionuclides and radionuclide therapy. She is also involved in various expert committees for the analysis of regulatory aspects related to radiopharmaceuticals.

Adriano Duatti is currently a professor of general and inorganic chemistry at the University of Ferrara and a research associate of the Italian National Institute of Nuclear Physics (INFN). He is Head of the LARAMED project at the INFN Legnaro

National Laboratories, which aims develop the production of innovative and nonstandard radionuclides for medical applications using a high-energy $(70 \mathrm{MeV})$ and high-curren (800 microA) cyclotron. He is also a radiopharmaceutical consultant to the Italian Ministry of Health. He has also worked at the International Atomic Energy in Vienna, Austria in the Radioisotope Products and Radiation Technology Section. His main research interests focus on the chemistry of metallic radiopharmaceuticals, molecular imaging, and targeted radionuclide therapy. 
biological processes in living systems. In principle, both endogenous and exogenous molecules can be used as molecular imaging agents. In this situation, molecular imaging exploits the properties of a signal-generating agent to visualize the distribution of the molecular probe by an appropriate imaging device. Thus, molecular imaging here is a methodology that makes use of molecularsized objects to collect fundamental biological information and, accordingly, it cannot be viewed as 'imaging of molecules', but rather as 'imaging with molecules'.

Essentially, there are two approaches to accomplish this endeavor: (i) stimulate some endogenous biomolecule inside the cell to emit a signal; or (ii) introduce into the cell a molecular probe tagged with a moiety able to generate a signal. The first approach, typically used with fluorescent proteins, usually does not allow a signal to be channeled with sufficient intensity to be detectable for diagnostic purposes. Conversely, the most obvious example of the other type of approach is the radiolabeling of a molecule with a $\gamma$-emitting radionuclide.

Different classes of substance can be utilized as molecular probes, including endogenous biomolecules, exogenous natural products, and synthetic molecules. However, it is uncommon that a radiolabeled probe perfectly matches the biological behavior of the native substance from which it was derived. In this respect, the radiotracers $\left[{ }^{11} \mathrm{C}\right.$-acetate $],\left[{ }^{15} \mathrm{OH}_{2}\right]$, and $\left[{ }^{13} \mathrm{NH}_{3}\right]$ represent sporadic examples of perfect matching because the radiolabeled derivatives are simply obtained by replacing one nonradioactive atom with the corresponding radioactive counterpart without any alteration of the primitive molecule [4]. Usually, the radiolabeling procedure modifies some structural features of the precursor molecule, thus giving rise to an authentic novel compound with its own biological characteristics. This supports the notion that a radiolabeled molecular probe, also called a radiopharmaceutical, is a unique species with unique biodistribution properties and specific uptake mechanisms.

Another category of radiopharmaceuticals that cannot be strictly interpreted as radiolabeled molecules is currently emerging [7]. This comprises simple radioactive monoatomic ions derived from bioelements having a well-recognized natural role in several biological processes. This type of radioactive tracer is not novel given that radioactive iodine, in the form of a negatively charged ion, was introduced into clinical use decades ago for the treatment of thyroid diseases. This application sprang from the key role of iodine in the metabolism of hormones by the thyroid. Yet, this is a limited application restricted to a single organ. After the advent of suitable production procedures based on a new generation of advanced cyclotrons, several radioisotopes of elements with a larger range of biological functions have recently become available [8]. These include ${ }^{64} \mathrm{Cu},{ }^{67} \mathrm{Cu}[9],{ }^{63} \mathrm{Zn} \mathrm{[10],} \mathrm{and}{ }^{52} \mathrm{Mn}$ [11]. In principle, these radiometals can be used to image their own journey through a living organism after being administered as simple metallic ions. This approach could be a genuine example of molecular imaging given that the radiometal represents simultaneously both the imaging probe and the bioactive substrate.

Among the above-mentioned radioactive ions, $\left[{ }^{64} \mathrm{Cu}^{2+}\right]$ is currently the most actively investigated and its potential for both diagnosis and therapy is being unearthed. Here, we review the status of research on the ${ }^{64} \mathrm{Cu}$. We show that $\left[{ }^{64} \mathrm{Cu}^{2+}\right]$ can be utilized not only to monitor its own natural biological behavior in normal and diseased tissues, but also as radiolabeling precursor for the preparation of novel metallic radiopharmaceuticals.

\section{Copper radioisotopes for medicine}

There are five important copper radioisotopes with nuclear characteristics suitable for nuclear medicine applications (Table 1): ${ }^{64} \mathrm{Cu},{ }^{67} \mathrm{Cu},{ }^{62} \mathrm{Cu},{ }^{61} \mathrm{Cu}$ and ${ }^{60} \mathrm{Cu}[12]$.

${ }^{64} \mathrm{Cu}$ decays mostly through the emission of $\beta^{+}$and $\beta^{-}$particles and Auger electrons [13]. In principle, the combination of these radioactive emissions can be exploited for carrying out both diagnosis and therapy using the same radiolabeled species, thus providing an example of clinical approaches collectively referred to as 'theranostics' [14]. This suggests that ${ }^{64} \mathrm{Cu}$ is an almost ideal example of a theranostic radionuclide.

Given that ${ }^{64} \mathrm{Cu}$ cannot be conveniently produced by the decay of isobars, it must be obtained by particle irradiation. Deuteroninduced reactions are a competitive method, whereas neutron bombardment in nuclear reactors typically yields the radionuclide in low-specific activities. Usually, proton-induced reactions are the most efficient. The maximum theoretical specific activity that can be achieved is $1.43 \times 10^{17} \mathrm{~Bq} \mathrm{~g}^{-1}$. To avoid the co-production of radionuclidic impurities, proton irradiation always requires the use of highly enriched ${ }^{64} \mathrm{Ni}$ targets. Currently, high-yield production of high-specific activity ${ }^{64} \mathrm{Cu}$ is readily achievable using biomedical cyclotrons through bombardment of enriched ${ }^{64} \mathrm{Ni}$ with low energy protons (10-18 MeV) [15-22]. A factor limiting the cost-effectiveness of this method is the high commercial value of enriched ${ }^{64} \mathrm{Ni}$ (natural abundance of ${ }^{64} \mathrm{Ni}$ is only $0.926 \%$ ) and the low proton currents $(<100 \mu \mathrm{A})$ currently available with the most common biomedical cyclotrons. Yet, the technology for cyclotron-based production of ${ }^{64} \mathrm{Cu}$ has advanced considerably in recent years and fully automated systems for the target

TABLE 1

Nuclear properties of copper radioisotopes

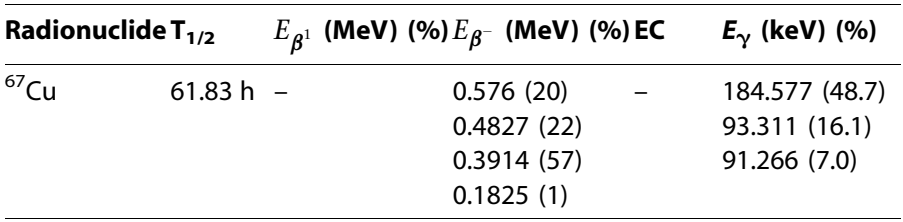

\begin{tabular}{|c|c|c|c|c|c|}
\hline${ }^{64} \mathrm{Cu}$ & $12.7 \mathrm{~h}$ & $0.65308(17.4)$ & 0.5787 (39) & $43.6 \%$ & $\begin{array}{l}1345.77(0.473) \\
511(34.79)\end{array}$ \\
\hline${ }^{62} \mathrm{Cu}$ & $9.74 \mathrm{mir}$ & 2.927 (97.2) & - & $2.8 \%$ & $\begin{array}{l}511(194.86) \\
1173.02(0.342)\end{array}$ \\
\hline${ }^{61} \mathrm{Cu}$ & $3.33 \mathrm{~h}$ & $\begin{array}{l}1.2164(51) \\
1.1489(2.3) \\
0.9334(5.5) \\
0.5604(2.6)\end{array}$ & - & $38.6 \%$ & $\begin{array}{l}656.008(10.77) \\
511(120.87) \\
373.05(2.10) \\
282.956(12.2) \\
67.412(4.20)\end{array}$ \\
\hline${ }^{60} \mathrm{Cu}$ & $23.7 \mathrm{mir}$ & $\begin{array}{l}3.7719(5) \\
2.9456(15) \\
2.4784(2.8) \\
1.9805(49) \\
1.9105(11.6) \\
1.8352(4.59)\end{array}$ & - & $12.01 \%$ & $\begin{array}{l}03124.1(4.8) \\
2158.90(3.34) \\
1861.6(4.8) \\
1791.6(45.4) \\
1332.501(88) \\
1035.2(3.7) \\
826.4(21.7) \\
511(185.19) \\
467.3(3.52)\end{array}$ \\
\hline
\end{tabular}


manufacturing and purification of the final radionuclide are now commercially available.

${ }^{67} \mathrm{Cu}$ is another radionuclide that has been proposed as theranostic agent because of its combined emission of $\beta^{-}$particles and $\gamma$ rays (Table 1 ). This radionuclide can be produced by bombardment of ${ }^{67} \mathrm{Zn}$ targets with neutrons in high-flux reactors [23]. Another reliable route involves irradiation of enriched ${ }^{68} \mathrm{Zn}$ targets with beams of cyclotron-accelerated protons in the energy range $40-70 \mathrm{MeV}[8,9]$. However, the lack of a dedicated network of nuclear reactors and the low number of operational high-energy cyclotrons limits the potential impact of this important theranostic radionuclide on clinical nuclear medicine.

${ }^{62} \mathrm{Cu}$ decays, almost exclusively, by positron emission and is currently produced using a ${ }^{62} \mathrm{Zn} /{ }^{62} \mathrm{Cu}$ microgenerator [24]. Its short half-life of 9.27 min makes it suitable for dynamic studies of organ function. However, the relatively short half-life of the parent nuclide ${ }^{62} \mathrm{Zn}(9.186 \mathrm{~h})$ does not allow this generator to be operated for any longer than 3 days, a limitation that might hamper its widespread use for broader diagnostic applications.

${ }^{61} \mathrm{Cu}$ emits $\beta^{+}$particles of different energies, a less-favorable characteristic that usually makes difficult to obtain images with optimal spatial resolution. Many nuclear reactions have been proposed for its production, and those marked with the highest yields involve bombardment of nat $\mathrm{Zn}$ or highly enriched ${ }^{64} \mathrm{Zn}$ targets with protons beams in the energy range $20-70 \mathrm{MeV}[8,12]$.

${ }^{60} \mathrm{Cu}$ decays by high-energy $\beta^{+}$emission associated with a cascade of $\gamma$-rays. These nuclear properties have a negative impact on image quality and, combined with its short half-life of $23.7 \mathrm{~min}$, constitute important drawbacks for its further diffusion in clinical applications $[8,25]$.

\section{lonic copper-64 as a theranostic agent}

Copper ions are essential for a multitude of biological processes. They are required as catalytic cofactors of many enzymes and are key structural components for functional proteins with fundamental roles in cellular biology $[26,27]$.

Although the exact mechanism of $\mathrm{Cu}^{2+}$ absorption by human cells has not yet been fully elucidated, it is argued that, in the blood stream, $\mathrm{Cu}^{2+}$ ions are bound to plasma proteins, such as ceruloplasmin, albumin, and transcuprein, which transfer them to the outer cell membrane, where they are reduced to $\mathrm{Cu}^{+}$ions by reductase enzymes. In this reduced oxidation state, $\mathrm{Cu}^{+}$ions are then transported across the cell membrane by the human copper transporter 1 (hCTR1) where they subsequently bind to the tripeptide glutathione (GSH) that, hypothetically, is thought to behave as primary $\mathrm{Cu}^{+}$acceptor [27]. After this initial step inside the cell, copper ions are delivered and trapped by copper chaperones $[28,29]$ (Fig. 1). Storage and the subsequent redistribution of copper ions to the other tissues mainly occurs through the liver. Consequently, the hepatobiliary system is the most relevant route of elimination of excess copper ions from the organism.

Copper ions have another key role in cell replication and growth. This metal is associated with various transcription factors and copper binding is thought to promote conformational changes of the structure of proteins associated with DNA transcriptional activation. Therefore, it is not surprising that several research studies have revealed that copper ions are deeply involved in cancer development and progression. Experimental data clearly

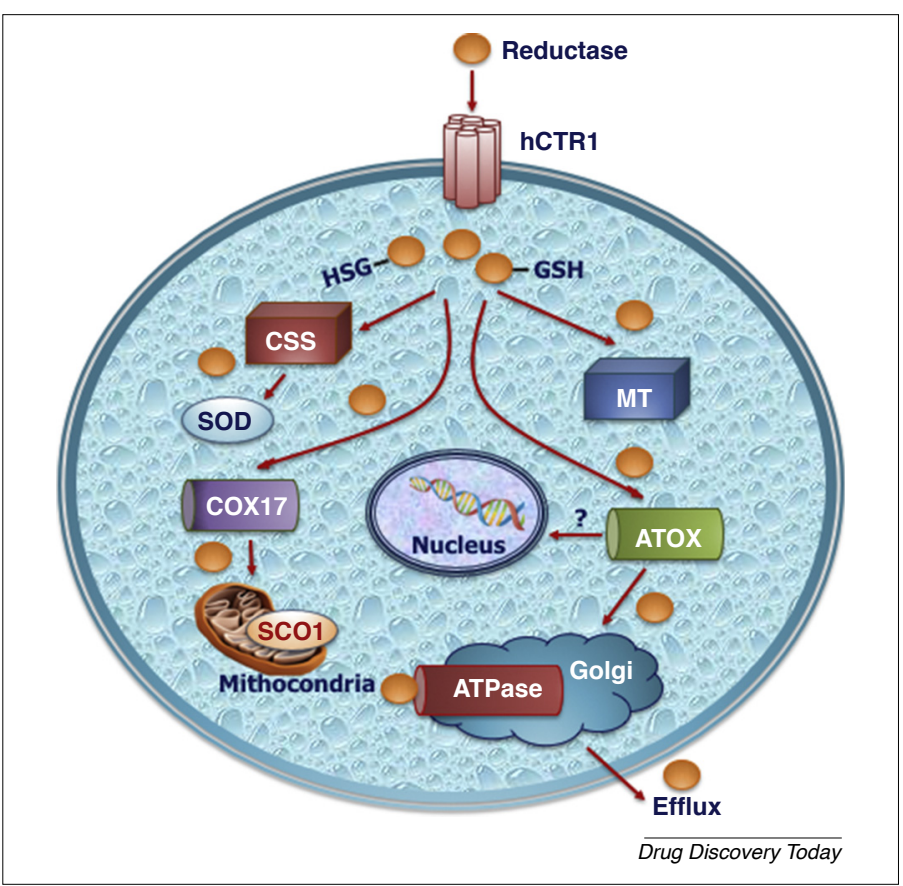

\section{FIGURE 1}

Representation of the cellular uptake and trafficking of copper ions $[27,29]$. Plasma proteins (ceruloplasmin, albumin, and transcuprein) carry $\mathrm{Cu}^{2+}$ ions to the external membrane, where they are reduced to $\mathrm{Cu}^{+}$by enzymes (reductases), before being transported into the cell by the human copper transporter 1 (hCTR1) protein. Glutathione (GSH) acts as first acceptor of $\mathrm{Cu}^{+}$, which is then transferred to chaperone proteins [cytochrome $c$ oxidase copper chaperone (COX17), copper chaperone for SOD1 (CCS), and antioxidant protein (ATOX1)]. These chaperones deliver $\mathrm{Cu}^{+}$ions to the cytosol (via SOD1), mitochondria [via cytochrome c oxidase (COX)] and transGolgi network [via copper transporting ATPase (ATP7A/B)]. The metallothionein (MT) proteins patrol the cell to irreversibly bind excess $\mathrm{Cu}^{+}$ ions. Experimental evidence indicates that, in tumor cells, efficient transfer of copper to the nucleus occurs through the action of the ATOX1 protein [34].

evidenced an elevated level of copper accumulation in malignant tissues [30-32]. The highest intracellular localization of copper is ubiquitously observed in the cytoplasm of normal tissue, whereas it is quantitatively transferred to the perinuclear and intranuclear regions in tumor tissues [33]. Recently, an interesting study [34] shed light on the possible role of the protein ATOX1 in the transport of copper to the nucleus of tumor cells, thus providing further evidence of the potential impact of this biometal on cancer growth and progression at the DNA level. A general interpretation for this altered copper metabolism in cancerous cells maintains that it could be attributed to the action of the copper transport protein hCTR1, a 190-amino-acid protein comprising three transmembrane domains, which is overexpressed in a high number of tumors, including prostate, lung, breast, and liver cancers, glioblastomas and melanoma [34-38]. This view that increased uptake in tumors most likely originates from the increased transport rather than from vascular leakage of copper ions, is supported by the finding that ${ }^{64} \mathrm{Cu}$ uptake was reduced in CTR1-knockdown tumor mice [39]. Thus, targeting hCTR1 with radioactive copper ions has been proposed as an efficient approach for molecular imaging of metabolic alterations in a variety of cancers. More precisely, tracking the in vivo biological behavior of copper ions using radioactive $\left[{ }^{64} \mathrm{Cu}^{2+}\right]$ could provide a valuable biomarker for 
disclosing fundamental molecular information in cancerous tissues $[35,40,41]$. Notably, the associated $\beta^{-}$-decay and Auger electron emissions could also be harnessed to trigger a therapeutic effect on cancerous lesions, thus forming the basis for the use of ${ }^{64} \mathrm{Cu}$ as a genuine theranostic agent [42].

Results obtained from preclinical studies in animal models of a variety of malignancies consistently supported the hypothesis that $\left[{ }^{64} \mathrm{Cu}^{2+}\right]$ ions could become a useful tool for molecular imaging and therapy of various cancers [32,43-50]. These experiments clearly confirmed that $\left[{ }^{64} \mathrm{Cu}^{2+}\right]$ is selectively accumulated by various cancerous tissues and that, unlike the radiotracer 2-deoxy-2$\left[{ }^{18} \mathrm{~F}\right.$-fluoro-D-glucose] ( ${ }^{18} \mathrm{~F}$-FDG), is not engaged in inflammatory processes, thus suggesting that this radioactive probe behaves as a highly specific tumor marker. In these studies, hCTR1 expression was measured in a group of cell lines, including prostate, lung, ovarian and breast cancers, melanoma, and glioblastoma and compared with $\left[{ }^{64} \mathrm{Cu}^{2+}\right]$ uptake. The experimental findings demonstrated that the increased accumulation of $\left[{ }^{64} \mathrm{Cu}^{2+}\right]$ was always mediated by hCTR1 overexpression in those cancerous cells, thus suggesting the potential theranostic use of $\left[{ }^{64} \mathrm{Cu}^{2+}\right]$ for hCTR1expressing malignancies.

A few investigational clinical studies and preliminary experimental data in humans convincingly supported preclinical observations. In these studies, $\left[{ }^{64} \mathrm{Cu}^{2+}\right]$ was administered as simple chloride salt dissolved in a sterile and pyrogen-free, buffered solution. Specific activity was $3700 \mathrm{MBq} / \mathrm{mg}$ and volumic activity $925 \mathrm{MBq} / \mathrm{ml}$. In normal subjects, the organ showing the highest accumulation of radioactive $\left[{ }^{64} \mathrm{Cu}^{2+}\right]$ was the liver, with lower uptake also found in brain, kidneys, and pancreas.

A first investigation was carried out on a limited cohort of patients to elucidate whether $\left[{ }^{64} \mathrm{Cu}^{2+}\right]$ could be used for imaging prostate cancer (PCa) in humans [51]. A group of patients treated with adrenal deprivation therapy and another not receiving this treatment, were selected for this study. Cancerous lesions were sharply detected within $1 \mathrm{~h}$ after injection of $\left[{ }^{64} \mathrm{Cu}^{2+}\right]$ (Fig. 2). These observations confirmed that previous results collected in animal models also hold in humans and that $\left[{ }^{64} \mathrm{Cu}^{2+}\right]$ could be utilized as a diagnostic agent for staging PCa. As expected, the hepatobiliary system was the most relevant excretion route.

A first Phase II investigational clinical study was recently reported [52] to investigate prospectively the biodistribution, dosimetry, and lesion kinetics of $\left[{ }^{64} \mathrm{Cu}^{2+}\right]$ in a significant number of patients with PCa with biochemical relapse. This work was also the first attempt to compare the diagnostic performances of PET/ CT, carried out with both $\left[{ }^{64} \mathrm{Cu}^{2+}\right]$ and ${ }^{18} \mathrm{~F}$-choline, with multiparametric MRI (mpMRI) in assessing PCa. Results collected in these patients provided further evidence on the effectiveness of $\left[{ }^{64} \mathrm{Cu}^{2+}\right]$ in detecting local recurrence along with metastases in bones and lymph nodes. Detection rate (DR) of $\left[{ }^{64} \mathrm{Cu}^{2+}\right]$ was significantly higher than observed for $\left[{ }^{18} \mathrm{~F}\right.$-choline], particularly in identifying local recurrence. In a patient-based analysis, $\left[{ }^{64} \mathrm{Cu}^{2}\right.$ ${ }^{+}$] was found to detect more patients with PCa relapse compared with $\left[{ }^{18} \mathrm{~F}\right.$-choline $]$ at prostate-specific antigen (PSA) levels $\leq 4 \mathrm{ng} \mathrm{mL}{ }^{-1}$, although for PSA values $>4 \mathrm{ng} \mathrm{mL}^{-1}$, DR values converged for the two diagnostic agents. In a lesion-based analysis, a remarkably high DR for $\left[{ }^{64} \mathrm{Cu}^{2+}\right]$ was also observed in patients with PSA $<1 \mathrm{ng} \mathrm{ml}{ }^{-1}$, where PET/CT with $\left[{ }^{64} \mathrm{Cu}^{2+}\right]$ outperformed both ${ }^{18} \mathrm{~F}$-Choline and mpMRI. The apparently superior perfor- mance of ${ }^{64} \mathrm{Cu}$-PET/CT can be traced back to the favorable biodistribution properties of $\left[{ }^{64} \mathrm{Cu}^{2+}\right]$ ions. In particular, $\left[{ }^{64} \mathrm{Cu}^{2+}\right]$ did not significantly wash out from the kidneys and, thus, did not concentrate in the urinary tract. This enabled a careful assessment of the pelvis and prostatic bed leading to the clear visualization of small lesions not hidden by any significant bladder activity. Timeactivity curves showed that uptake of $\left[{ }^{64} \mathrm{Cu}^{2+}\right]$ by PCa lesions was rapid and peaked approximately $1 \mathrm{~h}$ after administration, whereas its clearance was slow and dictated by the physical decay of the radionuclide. Interestingly, the effective dose administered to patients with $\left[{ }^{64} \mathrm{Cu}^{2+}\right]$ was similar to that measured for other common PET tracers $(5.7 \mathrm{mSv})$.

Another preliminary exploratory clinical study was pursued to assess the feasibility of PET/CT imaging of brain tumors with $\left[{ }^{64} \mathrm{Cu}^{2+}\right]$ in patients with glioblastoma multiforme. Comparison with MRI, as reference imaging method, revealed sharp agreement between the two diagnostic modalities. PET/CT imaging with $\left[{ }^{64} \mathrm{Cu}^{2+}\right]$ clearly detected brain cancerous tissues at $1 \mathrm{~h}$ post injection. Stable retention of radioactivity in brain lesions lasted for more than $24 \mathrm{~h}$. Again, these results confirmed preclinical observations and pointed to the potential of $\left[{ }^{64} \mathrm{Cu}^{2+}\right]$ as a diagnostic tracer for cerebral malignancies (Fig. 3). Remarkably, in the same clinical study, a patient first found to have astrocytoma by MRI, was subsequently imaged with $\left[{ }^{64} \mathrm{Cu}^{2+}\right]$ and no uptake was observed in the tumor region [53]. After removal of the lesion, histological characterization disclosed its benign nature, a result that sheds further light on the intrinsic affinity of ${ }^{64} \mathrm{Cu}$ ions for authentic malignant tissues.

Ongoing clinical studies are progressively revealing the high specificity and uptake of $\left[{ }^{64} \mathrm{Cu}^{2+}\right]$ for malignant tissues in the early stages of cancer progression, thus providing strong evidence that preclinical results can also be reproduced in humans. In particular, current experimental efforts are devoted to scrutinizing whether this tracer could be effective for the early diagnosis of cancerous lesions in different organs. Apparently, this selectivity of $\left[{ }^{64} \mathrm{Cu}^{2+}\right]$ for different tumors appears always to be mediated by hCTR1 overexpression. A striking example was found in imaging liver cancer with $\left[{ }^{64} \mathrm{Cu}^{2+}\right]$. Although it could be expected that visualization of lesions in the abdominal region would be hampered by the natural, intense liver uptake of copper ions, the extremely high affinity of $\left[{ }^{64} \mathrm{Cu}^{2+}\right]$ for cancer cells in their initial stage of malignant transformation, allowed early and efficient imaging of hepatic metastases in a patient with hepatic cancer. This intense accumulation is sustained by overexpression of hCTR 1 copper importers by hepatocytes in liver tissue $[48,54,55]$.

Despite the constantly growing evidence for the high potential of ionic ${ }^{64} \mathrm{Cu}$-PET to serve as a diagnostic tool for visualizing pathological changes in copper metabolism in diseased tissues, there are still open questions that need to be addressed. Primarily, there are obvious limitations to the diagnostic utility of radiocopper when regions of high physiological uptake, such as the abdomen, are imaged. Furthermore, slight variations in radiation dosimetry estimates have been reported in humans, owing to the complex decay characteristics of ${ }^{4} \mathrm{Cu}$ that make it difficult to calculate the optimal and safest dose for patients [56]. These critical issues need to be adequately investigated and clarified to consolidate the clinical use of $\left[{ }^{64} \mathrm{Cu}^{2+}\right]$ as novel cancer theranostic agent. 


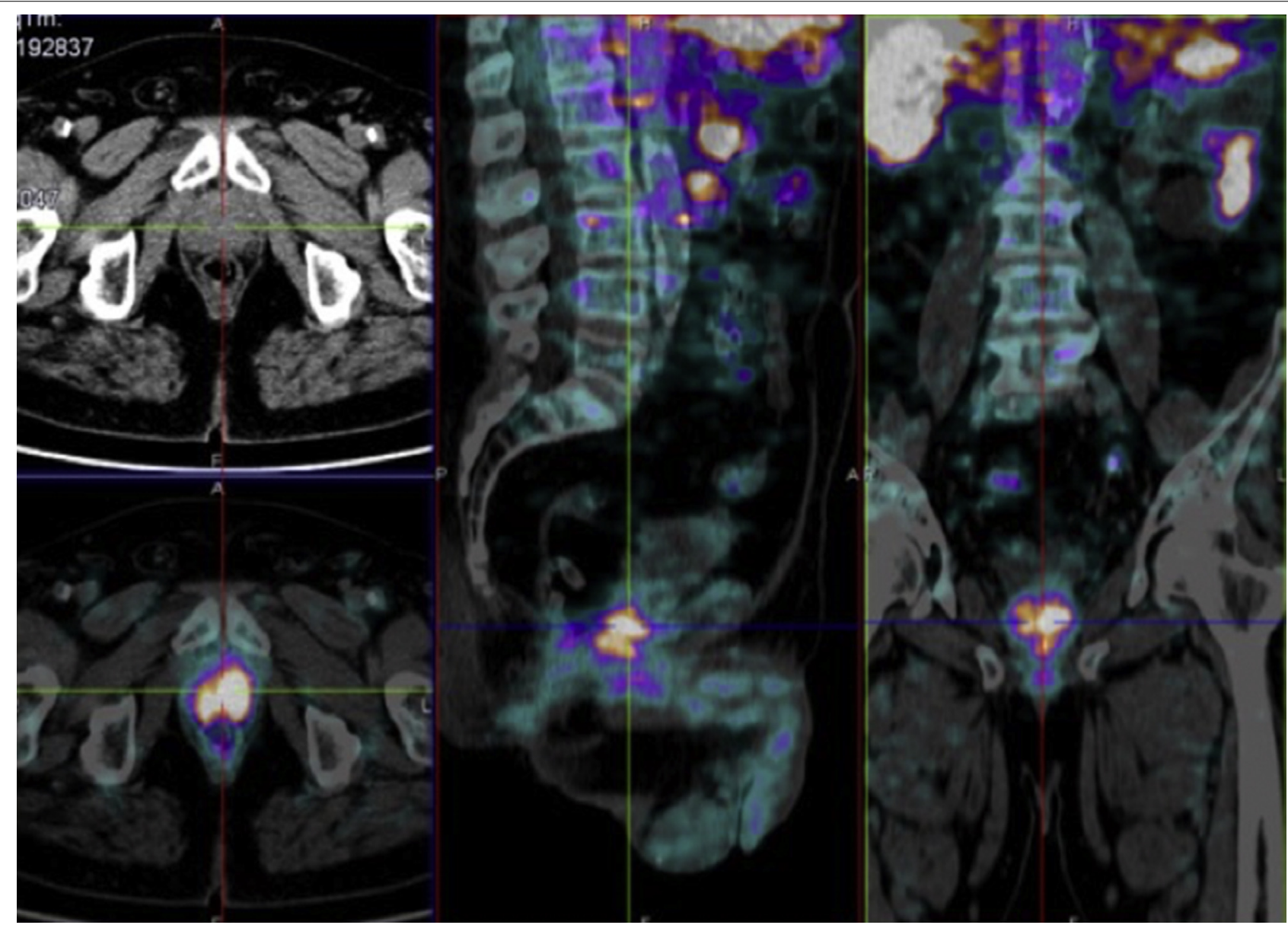

$\overline{\text { Drug Discovery Today }}$

\section{FIGURE 2}

A 72-year-old man with Gleason 413 prostate cancer (PCa) treated with radical prostatectomy, with increasing prostate-specific antigen (PSA) level (1.0) administered with $\left[{ }^{64} \mathrm{CuCl}_{2}\right](5 \mathrm{MBq} / \mathrm{kg})$. Images at (1 h post injection) revealed intense focal tracer uptake in the vesicourethral anastomosis [52]. Reproduced, with permission, from A. Piccardo.

Another concern that is frequently raised when free ${ }^{64} \mathrm{Cu}$ ions are proposed as injectable agents stems from their potentially toxic chemical nature. However, a few calculations demonstrate that, when used as a radiopharmaceutical, $\left[{ }^{64} \mathrm{Cu}^{2+}\right]$ is not harmful to the patient. The total body copper content in a normal subject is approximately $100 \mathrm{mg}$ and the daily dietary intake is approximately $1-2 \mathrm{mg}$ [27]. Assuming that $3700 \mathrm{MBq}(100 \mathrm{mCi})$ needs to be administered to overcome the dietary limit $(1 \mathrm{mg})$, the specific activity should be $3.7 \mathrm{MBq} \mu \mathrm{g}^{-1}$, which is lower than that obtained by any available method for producing ${ }^{64} \mathrm{Cu}$. In fact, the specific activity that is commonly achieved using a conventional cyclotron is approximately $3700 \mathrm{MBq} \mathrm{gg}^{-1}$ and, thus, to reach the dietary limit of $1 \mathrm{mg}$, an activity of $3700 \mathrm{GBq}(100 \mathrm{Ci})$ has to be injected. However, this amount of activity has no clinical significance.

\section{Copper-64 radiopharmaceuticals}

Ionic $\left[{ }^{64} \mathrm{Cu}^{2+}\right]$ can be also used as precursor for the preparation of a variety of ${ }^{64} \mathrm{Cu}$-radiopharmaceuticals. The development of new radiometallated agents is commonly accomplished through the design of a so-called 'bifunctional ligands'. These are chemical constructs comprising two molecular pieces linked together, name- ly, a bioactive moiety that serves as targeting vector for delivering the radiopharmaceutical to some specific tissue and a chelating group that is necessary to keep the radiometal tightly bound to the bifunctional ligand [57-59]. A recurring pitfall that is frequently encountered in the application of the bifunctional approach to the preparation of novel ${ }^{64} \mathrm{Cu}$-radiopharmaceuticals, originates from the selection of a suitable chelating system for the metal. Given that transport proteins are responsible for sequestering $\mathrm{Cu}^{2+}$ ions in the blood pool, transchelation and removal of the metal from the bifunctional ligand is always a threat challenging the stability of ${ }^{64} \mathrm{Cu}$-radiopharmaceuticals. However, despite the intrinsic chelating weakness of some coordinating arrangements (see next Section), the diagnostic properties of several ${ }^{64} \mathrm{Cu}$ radiopharmaceuticals have been evaluated in various investigational clinical studies. The chemical representations of some of the most widely used chelating systems for ${ }^{64} \mathrm{Cu}$ are detailed in Fig. 4.

Given the current emphasis on diagnostic agents targeting either somatostatin receptors, which are overexpressed in neuroendocrine tumors, or prostate-specific membrane antigen (PSMA), a type II integral membrane glycoprotein overexpressed in PCa, bifunctional ligands for targeting these receptors have been developed and widely used to produce the corresponding ${ }^{64} \mathrm{Cu}$-radio- 


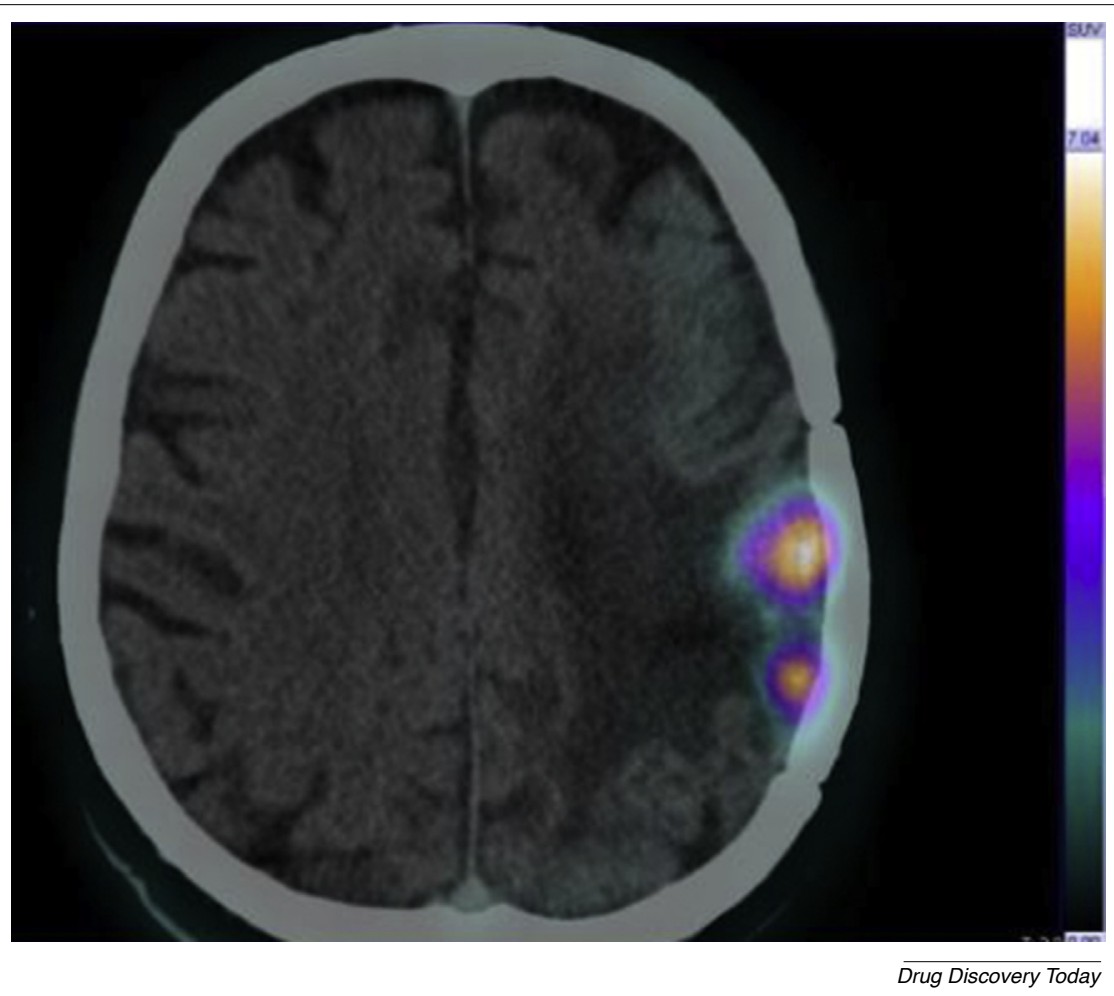

FIGURE 3

Brain $\left[{ }^{64} \mathrm{Cu}\right] \mathrm{Cu}^{2+} \mathrm{PET} / \mathrm{CT}$ scan of a cerebral glioblastoma collected at $1 \mathrm{~h}$ post injection (injected activity, $13 \mathrm{MBq} / \mathrm{kg}$ ) [53]. Reproduced, with permission, from C. Villano.

pharmaceuticals. Figure 5 provides schematic diagrams of the molecular structures of some of these bifunctional ligands. The common mechanism singled out to explain the uptake of these receptor-targeting agents entails that, after entering the receptor cleft, the radiocompound is rapidly internalized and trapped inside the cancerous cell. This property alleviates the issue of the instability of the chelating system and allows the use of these radiopharmaceuticals as effective diagnostic tools. Dissociation rates are usually slower compared with the readiness of the internalization processes. As a result, the release of $\left[{ }^{64} \mathrm{Cu}^{2+}\right]$ ions only becomes visible some time after the injection, as revealed by the increase in hepatic activity. However, owing to the peculiar biological behavior of $\mathrm{Cu}^{2+}$ ions described above, it is always difficult to separate the contribution to the final diagnostic image of the ${ }^{64} \mathrm{Cu}$-radiopharmaceutical from that of free $\left[{ }^{64} \mathrm{Cu}^{2+}\right]$ ions.

A preliminary study evaluating the diagnostic properties of the radiopharmaceutical $\left[{ }^{64} \mathrm{Cu}\right.$-TETA-octreotide] (TETA, 1,4,8,11-tetraazacyclotetradecane- $N, N^{\prime}, N^{\prime \prime}, N^{\prime \prime \prime}$-tetra-acetic acid) compared with the standard SPECT agent [ $\left[{ }^{111}\right.$ In-DTPA-octreotide] (DTPA, diethylene triamine penta-acetic acid) was carried out in a small cohort of eight patients with neuroendocrine tumors [60]. In six patients, both tracers were able to detect cancerous lesions, whereas in two patients, $\left[{ }^{64} \mathrm{Cu}\right.$-TETA-octreotide] detected more lesions compared with $\left[{ }^{111}\right.$ In-DTPA-octreotide]. In one patient, $\left[{ }^{111} \mathrm{In}\right.$ DTPA-octreotide] showed mild uptake in a lung lesion that was not visualized by $\left[{ }^{64} \mathrm{Cu}\right.$-TETA-octreotide]. Pharmacokinetic studies showed that $\left[{ }^{64} \mathrm{Cu}\right.$-TETA-octreotide] was rapidly cleared from the blood and partially excreted into the urine. The percentage injected activity of $\left[{ }^{64} \mathrm{Cu}\right.$-TETA-octreotide] in the liver increased over time, a clear sign of the poor stability of the metallic complex and of dissociation of $\left[{ }^{64} \mathrm{Cu}^{2+}\right]$ from the TETA chelator.

In a first prospective study in humans, $\left[{ }^{64} \mathrm{Cu}\right.$-DOTATATE $]$ was found to provide superior image quality compared with $\left[{ }^{111} \mathrm{In}\right.$ DTPA-octreotide]. After intravenous administration of 193-232 $\mathrm{MBq}$ of [ ${ }^{64} \mathrm{Cu}$-DOTATATE], 14 patients underwent both wholebody ${ }^{64} \mathrm{Cu}-\mathrm{PET} / \mathrm{CT}$ and ${ }^{111} \mathrm{In}$-SPECT/CT scans at 1,3 , and $24 \mathrm{~h}$ post injection. High and prolonged uptake in cancerous lesions was interpreted as evidence of a high rate of tracer internalization and resulted in images of excellent quality and high spatial resolution. Notably, target:background ratios also resulted in excellent image contrast with organs characterized by high somatostatin receptor density. Yet, although in vivo stability was sufficient to allow the collection of diagnostic images, the late increase in hepatic activity was attributed to the leakage of $\left[{ }^{64} \mathrm{Cu}^{2+}\right]$ ions from the chelating system. Calculated radiation dose estimates yielded an effective dose of $6.3 \mathrm{mSv}$ for an injected activity of $200 \mathrm{MBq}$ of $\left[{ }^{64} \mathrm{Cu}\right.$ DOTATATE], with the liver being the organ with the highest absorbed radiation dose $(0.16 \mathrm{mGy} / \mathrm{MBq})$. The image quality obtained with $\left[{ }^{64} \mathrm{Cu}\right.$-DOTATATE] was higher than that observed with $\left[{ }^{64} \mathrm{Cu}\right.$-TETA-octreotide], owing to the lower affinity of the latter tracer for type 2 somatostatin receptors (sstr2), as revealed by preclinical studies [61].

A subsequent larger study enrolling 112 patients prospectively confirmed the superior performance of $\left[{ }^{64} \mathrm{Cu}\right.$-DOTATATE] over conventional scintigraphy with [ ${ }^{111}$ In-DTPA-octreotide] in detecting neuroendocrine cancerous lesions. Accordingly, [ $\left[{ }^{64} \mathrm{Cu}\right.$-DOTATATE] detected more regions involved in the disease, a result that was also corroborated by a long follow-up intended to assess 

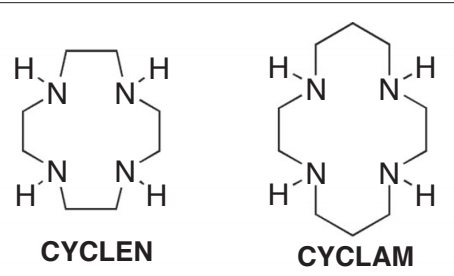<smiles>O=C(O)CCN(CCN(CC(=O)O)CC(=O)O)CCN(CC(=O)O)CC(=O)O</smiles><smiles>O=C(O)CN1CCCN(CC(=O)O)CCN(CC(=O)O)CCN(CC(=O)O)CC1</smiles><smiles>O=C(O)CN1CCN(CC(=O)O)CCN(CC(=O)O)CC1</smiles>

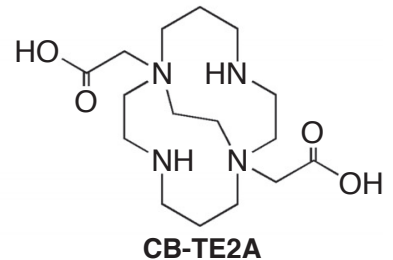

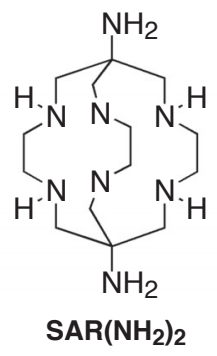

$\overline{\text { Drug Discovery Today }}$

\section{FIGURE 4}

Schematic illustration of the structures of tetra-aza-macrocyclic and hexamine macrobicyclic ligands most frequently used for the preparation of ${ }^{64} \mathrm{Cu}$-radiopharmaceuticals.

whether foci were truly positive or false-positive. After a follow-up of 42-60 months, no examples of false-positive results emerged from ${ }^{64} \mathrm{Cu}$-PET images [62].

More interestingly, a head-to-head comparison between $\left[{ }^{64} \mathrm{Cu}\right.$ DOTATATE $]$ and $\left[{ }^{68} \mathrm{Ga}\right.$-DOTATOC], currently the most widely used PET tracer for detecting neuroendocrine tumors, has been reported. On a patient basis, no substantial differences were found between the sensitivity of the two agents. However, $\left[{ }^{64} \mathrm{Cu}\right.$-DOTATATE $]$ had a remarkably higher detection rate of positive lesions, which was tentatively attributed to the lower positron range of ${ }^{64} \mathrm{Cu}$ compared with ${ }^{68} \mathrm{Ga}$, resulting in a better spatial resolution. Target:background ratios in the various organs were not significantly different for the two radiopharmaceuticals, thus yielding a similar image contrast. However, a key advantage of $\left[{ }^{64} \mathrm{Cu}\right.$-DOTATATE] stemmed from the longer half-life of the ${ }^{64} \mathrm{Cu}$ radionuclide that allowed the patient to be imaged between $1 \mathrm{~h}$ and $3 \mathrm{~h}$ after administration. This provided an additional advantage over $\left[{ }^{68} \mathrm{Ga}\right.$-DOTATOC $]$ by mitigating the need for a tight routine workflow and increased the number of patients who could be treated daily [63].

Preclinical and clinical studies are also underway with $\left[{ }^{64} \mathrm{Cu}-\right.$ SARTATE], which is an analog of $\left[{ }^{64} \mathrm{Cu}\right.$-DOTATATE $]$ in which the chelating system is replaced by a sarcophagine (SAR) moiety (Fig. 5) [64]. In vitro and in vivo evaluation of $\left[{ }^{64} \mathrm{Cu}-\mathrm{SARTATE}\right]$ in animal models demonstrated its high selectivity for tumor cells expressing sstr2. Comparison between the biodistribution data of $\left[{ }^{64} \mathrm{Cu}\right.$-SARTATE $]$ and $\left[{ }^{64} \mathrm{Cu}\right.$-DOTATATE $]$ (DOTATATE, DOTA-Tyr3octreotate) showed that both radiopharmaceuticals exhibited excellent uptake in sstr2-positive tumors at $2 \mathrm{~h}$ post injection. However, tumor uptake of $\left[{ }^{64} \mathrm{Cu}\right.$-DOTATATE] significantly faded away at $24 \mathrm{~h}$, whereas activity of [ ${ }^{64} \mathrm{Cu}$-SARTATE] persisted, thus improving image contrast at later time points. Accumulation of $\left[{ }^{64} \mathrm{Cu}\right.$-SARTATE $]$ in nontarget organs, such as liver and lungs, was lower than that for $\left[{ }^{64} \mathrm{Cu}\right.$-DOTATATE $]$. Washout of $\left[{ }^{64} \mathrm{Cu}\right.$ SARTATE] occurred mostly through the kidneys. The selectivity of $\left[{ }^{64} \mathrm{Cu}\right.$-SARTATE] for sstr2 was confirmed by in vitro experiments with A427-7 cells, demonstrating high cell-surface binding followed by receptor-mediated endocytosis, as well as by biodistribution and imaging studies in A427-7 tumor-bearing mice. The high tumor uptake and prolonged retention of $\left[{ }^{64} \mathrm{Cu}\right.$-SARTATE] could reflect the robustness of the $\mathrm{Cu}^{2+}$ complex with the SAR ligand preventing dissociation of the metal ion from the chelate. Therefore, it was concluded that SAR-type ligands are able to form $\mathrm{Cu}^{2+}$ complexes with higher stability than DOTA-type ligands. This superior coordinating ability could ensure their applicability for use in routine imaging at later time points post injection in accordance with the longer half-life of ${ }^{64} \mathrm{Cu}[65]$.

Currently, much effort is devoted to the development of radiometal-based radiopharmaceuticals for targeting the integral membrane glycoprotein PSMA [66]. Phosphoramidate-based and ureabased molecules, two important categories of low-molecularweight PSMA inhibitors, have been synthesized to target PSMA with high affinity and specificity. Ligands incorporating the peptidomimetic motif Lys-urea-Glu have been widely investigated in radiopharmaceutical development and the ${ }^{64} \mathrm{Cu}$-labeled ligand DOTA-PSMA-617 (Fig. 5) was recently evaluated as a PET imaging agent for PCa. Excellent, high-resolution PET images of the cancerous lesions were detected with high lesion-to-background contrast. Again, the rapid internalization of the radiotracer into subcellular organelles of PSMA-positive prostate tumor cells, helped to overcome the problem of the in vivo instability of the ${ }^{64} \mathrm{Cu}$-DOTA chelating system.

In a first in-human study, the diagnostic potential of $\left[{ }^{64} \mathrm{Cu}-\right.$ PSMA-617] was analyzed in a group of 29 patients with PCa. PET images were acquired at $1 \mathrm{~h}$ and $2 \mathrm{~h}$ post injection, and metastatic lesions were detected with high resolution and high lesion:background contrast. Patients with histologically proven local disease were clearly identified by the tracer with high detection rates, also in the presence of low circulating levels of PSA. Suspected lymph node metastases, as detected by PET scans in two patients, were subsequently confirmed by the corresponding MRI images. Salivary glands, kidneys, and liver were among nontarget organs showing the highest radiotracer uptake $[67,68]$.

Another observational, prospective study was performed in a selected number of patients with intermediate-high-risk PCa to assess the diagnostic accuracy of $\left[{ }^{64} \mathrm{Cu}\right.$-PSMA-617] for primary lymph node (LN) staging before laparoscopic radical prostatectomy associated with extended pelvic LN dissection. The sensitivity, specificity, and positive $(\mathrm{P})$ and negative $(\mathrm{N})$ predictive values for $\mathrm{LN}$ involvement were calculated based on final pathological 


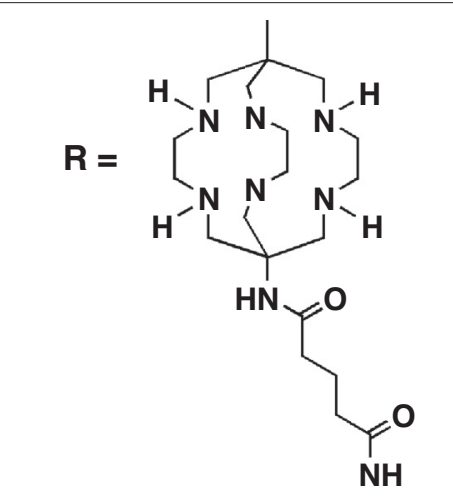

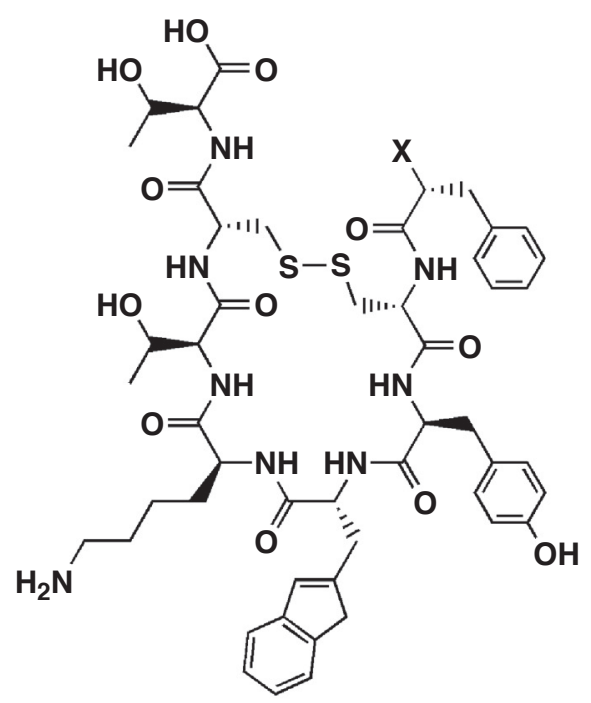<smiles>NC(=O)CN1CCN(CCN(CCN(CC(=O)O)CC(=O)O)CC(=O)O)CC1</smiles>

\section{$X=R$, SARTATE}

$\mathrm{X}=\mathrm{R}^{\prime}$, DOTATATE

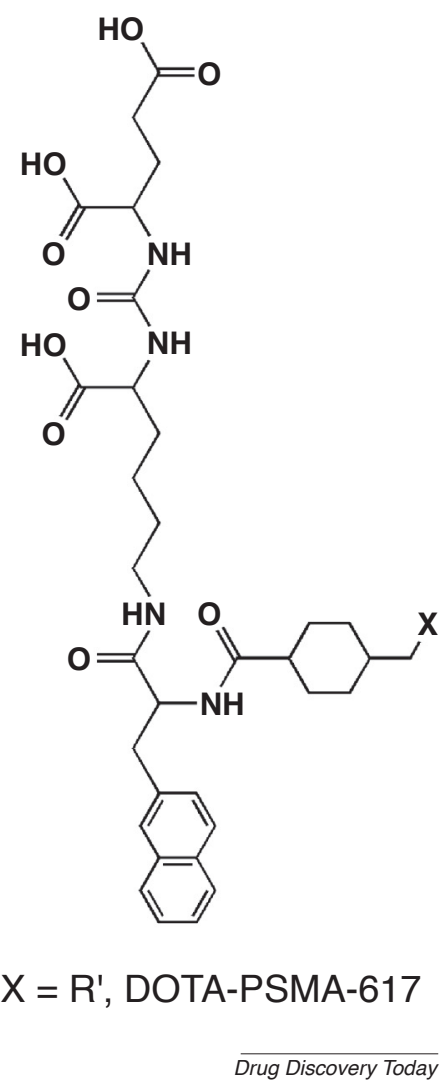

FIGURE 5

Schematic illustration of the structure of the bifunctional ligands DOTATATE, SARTATE, and DOTA-PSMA-617. For definitions, please see the main text.

findings. Imaging-based LN staging showed that $\left[{ }^{64} \mathrm{Cu}\right.$-PSMA-617] detected positive $\mathrm{LN}$ with a sensitivity of $87.5 \%$, specificity of $100 \%$, P of $100 \%$, and $\mathrm{N}$ of $93.7 \%$, thus suggesting a remarkable diagnostic accuracy of $\left[{ }^{64} \mathrm{Cu}-\mathrm{PSMA}-617\right]$ for primary LN staging before radical prostatectomy. Again, it is difficult to determine whether this excellent performance could be attributed only to the high specificity of $\left[{ }^{64} \mathrm{Cu}\right.$-PSMA-617] for PCa cells without taking into account the possible contribution of uptake by free $\left[{ }^{64} \mathrm{Cu}^{2+}\right]$ ions liberated as a result of the intrinsic instability of the $\mathrm{Cu}^{2}$ +-DOTA chelating arrangement [69].

A first-in-human clinical trial was carried out to study the agent $\left[{ }^{64} \mathrm{Cu}\right.$-DOTA-AE105] in patients with breast, prostate, and bladder cancer [70]. This new tracer features the high-affinity peptide antagonist AE105 targeting the urokinase-type plasminogen activator receptor (UPAR), which is expressed in many types of cancer and is predictive of metastatic invasion. The peptide AE105 was conjugated to the macrocyclic chelator DOTA and labeled with ${ }^{64} \mathrm{Cu}$ $[71,72]$. As expected, biodistribution data revealed high liver accu- mulation, which was most likely caused by the in vivo instability of the ${ }^{64} \mathrm{Cu}$-DOTA chelating system. In prostate as well as in breast and bladder cancers, primary tumors and metastatic lymph nodes were clearly identified with favorable tumor:background ratio, thus providing strong evidence for the target specific uptake of the $\left[{ }^{64} \mathrm{Cu}\right.$ DOTA-AE105] consistent with UPAR expression also demonstrated by immunohistochemistry assays carried out on isolated tissues.

An impressive example of controversial findings observed when DOTA is used for the conjugation of ${ }^{64} \mathrm{Cu}$ to biomolecules was found in a clinical study aimed at determining whether HER2positive breast cancer (BCa) metastases could be visualized noninvasively in the brain using the radiolabeled antibody $\left[{ }^{64} \mathrm{Cu}-\right.$ DOTA-trastuzumab] [73-75]. Metastatic brain lesions were efficiently targeted by $\left[{ }^{64} \mathrm{Cu}\right.$-DOTA-trastuzumab], thus supporting the conjecture that the radiolabeled antibody was able to penetrate the blood-brain barrier (BBB). However, the large size and hydrophilicity of therapeutic antibodies usually prevent crossing of the BBB. In addition, tumor infiltration by monoclonal antibodies is 
normally hindered by high values of intratumoral interstitial pressure. Although the authors speculated about a possible disruption of the $\mathrm{BBB}$ at the site of brain metastasis or the role of immunoglobulin $\mathrm{G}$ in antibody transport, a simpler hypothesis could take into account the observed high accumulation of ${ }^{64} \mathrm{Cu}$ ions in brain tumors. Indeed, the intrinsic instability of the ${ }^{64} \mathrm{Cu}$ DOTA chelating arrangement could promote the partial release of free ${ }^{64} \mathrm{Cu}$ ions into the blood stream and subsequent targeting of brain metastases by these ionic species.

A remarkable increase in stability was found when a different chelating system was used for the design and preparation of the tracer [ ${ }^{64} \mathrm{Cu}$-TP3805] [76]. Previous studies demonstrated that vasoactive intestinal polypeptide receptor 1 (VPAC1) and pituitary adenylate cyclase activating polypeptide (PACAP) are overexpressed at a high density on BCa cells, whereas on normal breast tissue or benign masses, only a low number of receptors are expressed. Therefore, a radiolabeled biomolecule was designed by combining a PACAP analog with a C-terminal diaminodithiol $\left(\mathrm{N}_{2} \mathrm{~S}_{2}\right)$ chelator to yield the corresponding bifunctional ligand (TP3805). The resulting conjugate radiocompound was prepared by reaction of TP3805 with ${ }^{64} \mathrm{Cu}$. Measurement of dissociation constants supported the high in vivo stability of $\left[{ }^{64} \mathrm{Cu}-\mathrm{TP} 3805\right]$ [77], which was, therefore, evaluated as a biomarker for the early and accurate detection of BCa. In a preliminary investigation, primary malignant tumors were visualized in 19 out of 20 patients imaged with $\left[{ }^{64} \mathrm{Cu}\right.$-TP3805]. In addition, whole-body PET/CT imaging revealed sentinel lymph nodes involvement in three patients, thus suggesting a high affinity of the tracer for VPAC1 receptor-expressing tumors.

The remarkable improvement in stability observed in passing from $\mathrm{N}_{4}$ tetramine ligands to $\mathrm{N}_{2} \mathrm{~S}_{2}$ ligands is further magnified when thiosemicarbazones, another class of $\mathrm{N}_{2} \mathrm{~S}_{2}$ ligands, are used as chelating agents for ${ }^{64} \mathrm{Cu}$. Bis(thiosemicarbazonato) copper(II) complexes are a family of compounds with an important role in the development copper-based radiopharmaceuticals (Fig. 6). This class of radioactive agents has been extensively described in the

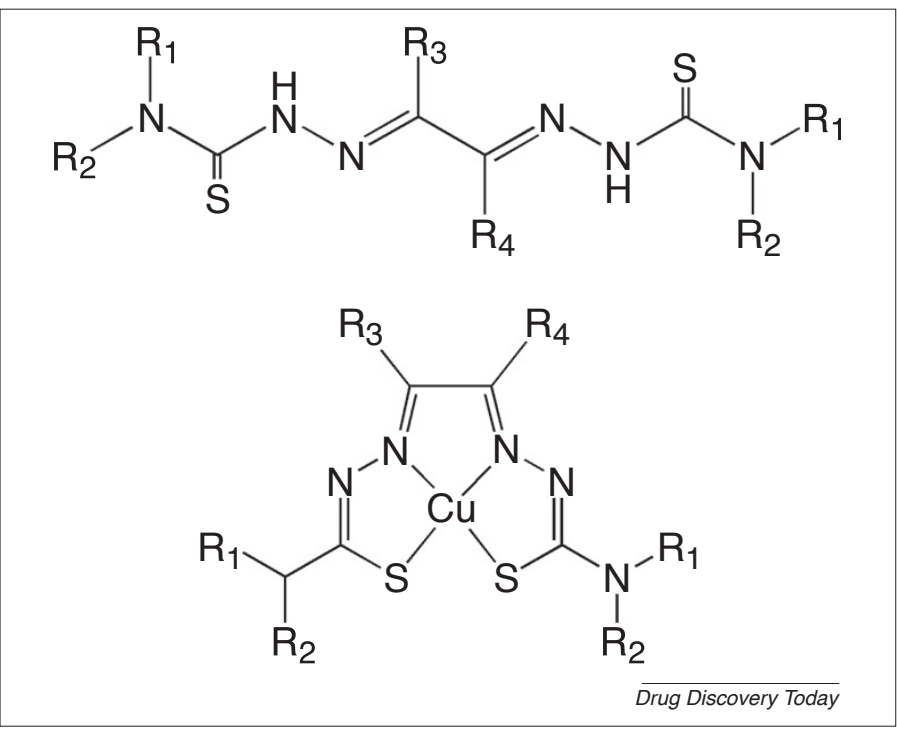

\section{FIGURE 6}

Schematic illustration of the structures of bis-thiosemicarbazone ligands and of the corresponding $\mathrm{Cu}(\mathrm{II})$ complexes. literature [78]. The bis(thiosemicarbazones) ligands can act as tetradentate ligands for $\mathrm{Cu}^{2+}$, forming stable, neutral complexes exhibiting high membrane permeability. The radioactive copper complexes can be prepared in high radiochemical yield under mild conditions. The biodistribution and specific targeting of these small-molecule complexes can be manipulated by altering the chemical substituents appended onto the bis-thiocarbazonato moiety. Several ${ }^{64} \mathrm{Cu}$-complexes have been investigated as either cardiac or hypoxia imaging agents and their stability in blood firmly established. It was hypothesized that removal of the $\mathrm{Cu}^{2+}$ ion from this chelating system can occur only inside hypoxic cells through a complex redox mechanism producing reduced $\mathrm{Cu}^{+}$ species. The compound $\left[{ }^{64} \mathrm{Cu}\right.$-ATSM] (where the ligand ATSM is diacetyl-bis ( $N^{4}$-methylthiosemicarbazone) (Fig. 7) has been extensively investigated as a marker for hypoxia [79-82]. It is a lipophilic, low-molecular-weight complex characterized by high membrane permeability and, therefore, rapid diffusion into cells. It exhibits low redox potential, which was supposed to be a key factor in favoring intracellular reduction of $\mathrm{Cu}^{2+}$ to $\mathrm{Cu}^{+}$. It was posited that reduction is driven by mitochondria within hypoxic cells with abnormally high electron concentrations, causing dissociation of the reduced metallic ion from the ligand and its subsequent cellular retention. Conversely, in normoxic cells, $\left[{ }^{64} \mathrm{Cu}-\mathrm{ATSM}\right]$ is kept in its oxidized form by a normal oxygen pressure, thus allowing its outflow from the cell. Various preclinical models disclosed some heterogeneity in hypoxia mapping by $\left[{ }^{64} \mathrm{Cu}-\mathrm{ATSM}\right]$, thus suggesting an underlying more complex phenomenon. This led to a complicated interpretation of tumor hypoxia. Experimental evidence suggested that $\left[{ }^{64} \mathrm{Cu}\right.$-ATSM] could be more appropriately considered as a marker of overreduced intracellular state rather than a pure hypoxia agent. In fact, the biochemical pathway leading to hypoxia usually switches the intracellular redox potential to become progressively more reductive, causing mitochondrial dysfunction because of excess of electrons. This picture indicates that redox state and hypoxia are both related and dependent phenomena, thus supporting the interpretation that $\left[{ }^{64} \mathrm{Cu}\right.$-ATSM] is a generalized marker of an over-reduced cell state and not specifically of hypoxia [80].

\section{A chemical toolkit to assess the stability of copper radiopharmaceuticals}

The discovery of the remarkable biodistribution properties of the radionuclide ${ }^{64} \mathrm{Cu}$, administered as simple cupric ions, also disclosed its possible therapeutic use for cancer treatment. However, experiments carried out with $\left[{ }^{64} \mathrm{CuCl}_{2}\right]$ have thus far demonstrated that this therapeutic potential can be fully exploited only when the radionuclide is accumulated inside the cell nucleus in close proximity to the genetic material. This condition is essential to allow low-energy Auger electrons to deposit a cytotoxic dose in the target tissue. Hence, it would be difficult to use, as therapeutic agents, ${ }^{64} \mathrm{Cu}$ radiopharmaceuticals that are unable to penetrate the outer cellular membrane and reach the nucleus. For this purpose, ${ }^{67} \mathrm{Cu}$ displays nuclear properties that appear more attractive for therapy of a larger class of tumors because of the emission of a medium-energy $\beta$-particle.

An additional crucial requirement, which holds for all diagnostic and therapeutic radiopharmaceuticals, is that the radiolabeled agent should always exhibit enough robustness in the biological 

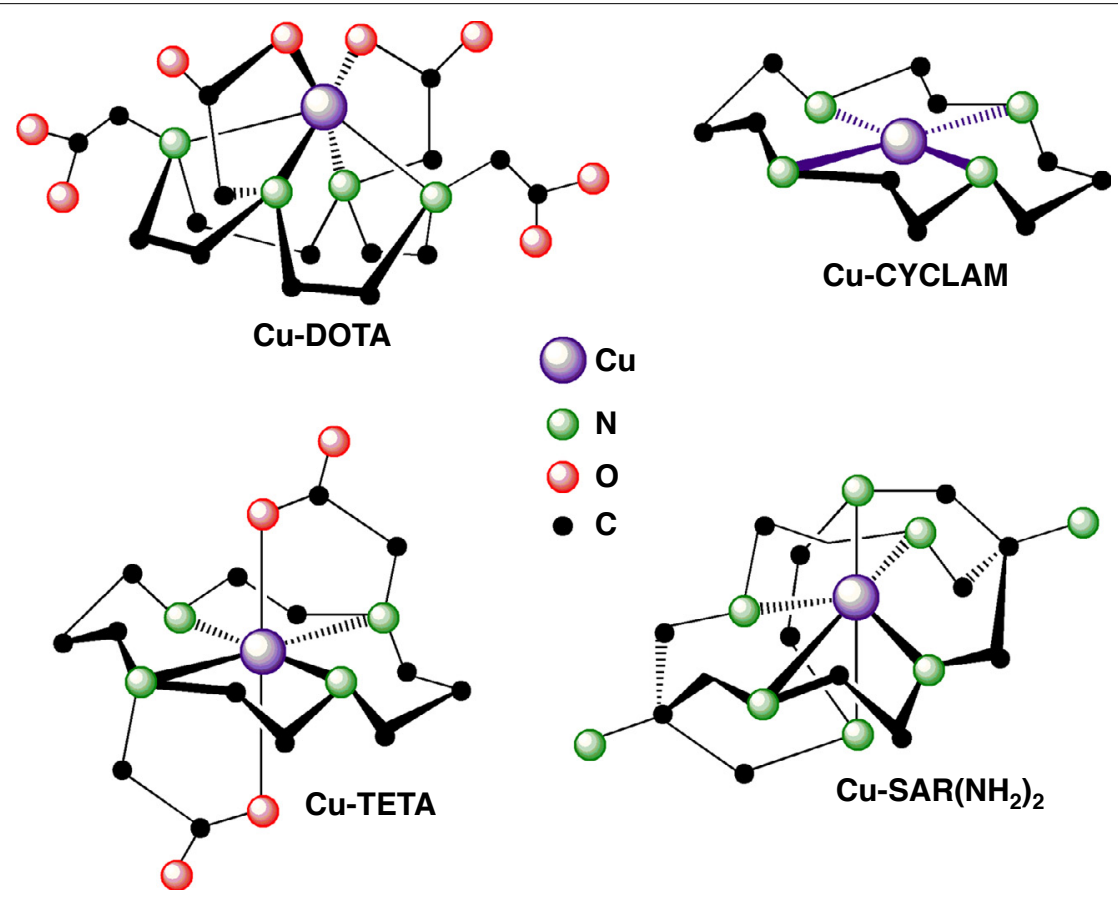

( $\mathrm{cu}$

O N

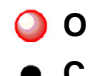

C

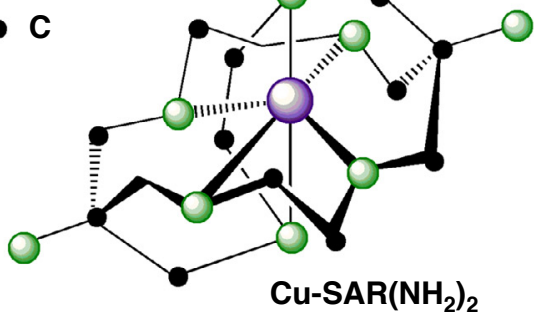

$\overline{\text { Drug Discovery Today }}$

FIGURE 7

Schematic illustration of the structures of the complexes $\mathrm{Cu}(\mathrm{II})-\mathrm{DOTA}, \mathrm{Cu}(\mathrm{II})-\mathrm{CYCLAM}, \mathrm{Cu}(\mathrm{II})-\mathrm{TETA}$, and $\mathrm{Cu}(\mathrm{II})-\mathrm{SAR}$. For definitions, please see the main text.

fluids and compartments during its journey to the final target [8385]. Unfortunately, there is much confusion about the most appropriate interpretation to be attributed to the stability concept and how to measure it. Usually, chemical stability is referred to as 'thermodynamic stability' and measured as $\log K$, where $K$ is the equilibrium constant of the reaction between the metallic ion and the coordinating ligands (the inverse is called the 'dissociation constant'). However, this quantity is defined only at equilibrium conditions and it is unrealistic to believe that this situation could be achieved in a biological system. Another type of stability that is commonly taken into account is the concept of kinetic stability. This can be defined as the rate of the dissociation reaction that can lead to the removal of the metal ion from the radiolabeled complex. Obviously, in a biological system, there might exist a multitude of possible dissociation routes, including hydrolytic processes and transchelation by metal-binding proteins. Yet, it is usually complicate to evaluate these processes because measurement of rate constants requires exact knowledge of the concentration of the reagents. A rough estimate of the biological inertness of a metallic radiopharmaceutical is to determine its stability in serum. This type of experiment involves incubating the radiocompound with serum at $37^{\circ} \mathrm{C}$ and then measuring the variation of its radiochemical purity. Therefore, it can partially mimic the physiological situation at least for that part of the circulating activity persisting in the blood stream. Although this information is usually helpful, it does not ensure that the radiocompound will remain intact in all biological compartments. Thus, the challenge in the development of metallic radiopharmaceutical is always to identify the most efficient strategy for recognizing which categories of ligand yield the most stable species. This endeavor is particularly arduous with copper radiopharmaceuticals because the chemistry of this element is complex and, for its full description, it requires knowledge of a few theoretical concepts that might not be familiar among the radiopharmacy community. However, it is possible to devise a simpler model based on more intuitive concepts, such as molecular geometry, that could be easier to handle, as illustrated below.

Regardless of the definition of stability, there is one inescapable property that a metallic compound should manifest to achieve sufficient biological inertness and this is its electronic stability. The electronic properties of transition metal complexes are reflected in their molecular geometries. Thus, analysis of crystal structures of copper complexes could shed light on the most stable arrangements of coordination atoms around this metal.

A significant number of studies of new ${ }^{64} \mathrm{Cu}$-radiopharmaceuticals have focused mainly on the use of tetra-aza-macrocyclic ligands as suitable chelating systems (Fig. 4) [84,85]. In particular, 1,4,7,10-tetra-aza-cyclododecane-1,4,7,10-tetra-acetic acid (DOTA) derivatives are widely used to synthetize bifunctional ligands able to tightly bind the copper ion and, concomitantly, to hold up a pendant pharmacophore [86,87]. Although it is frequently maintained that the resulting $\left[{ }^{64} \mathrm{Cu}\right.$-DOTA $]$ complexes are sufficiently stable, it could be argued that this conclusion is not fully correct, as suggested by the following simple arguments.

Figure 7 provides schematic of the crystal structure of the $\mathrm{Cu}$ (II)DOTA complex $[88,89]$. The $\mathrm{Cu}^{2+}$ ion is coordinated to the DOTA ligand through its four nitrogen atoms and two oxygen atoms of the pendant carboxylic groups. The two other carboxylic arms are protonated and do not integrate into the coordination sphere. The structure of $\mathrm{Cu}(\mathrm{II})$-DOTA resembles a distorted octahedron where the four nitrogen atoms do not occupy the equatorial plane and are heavily bent away to form a kind of pocket below the metal ion. 
Most importantly, two out of the four $\mathrm{Cu}-\mathrm{N}$ bond distances are elongated because of the so-called 'Jahn-Teller' effect. However, when not constrained by inclusion into a multidentate ligand, a set of four independent nitrogen atoms is usually arranged around the $\mathrm{Cu}^{2+}$ ion in a square plane, as demonstrated by the structure of the tetra-amine $\mathrm{Cu}(\mathrm{II})$ sulfate monohydrate salt $\left[\mathrm{Cu}\left(\mathrm{NH}_{3}\right)_{4}\left(\mathrm{H}_{2} \mathrm{O}\right)\right]$ [SO $\left.\mathrm{S}_{4}\right][90]$. In this complex, the nitrogen atoms of the four ammonia molecules and the metal ion all lie in the square plan of a square pyramid, where a weakly bound water molecule occupies the apical position (Fig. 7). Therefore, it appears that the structural features of the $\mathrm{Cu}$ (II)-DOTA complexes are in conflict with the observed geometrical preferences of the $\mathrm{Cu}^{2+}$ ion when coordinated by four nitrogen atoms.

This structural tendency is not limited to unconstrained amines, but is also observed in the complex $\left[\mathrm{Cu}(\mathrm{en})_{2}\right]$ (en, ethylenediamine) [91] and, most importantly, in $[\mathrm{Cu}(\mathrm{cyclam})]\left[\mathrm{ClO}_{4}\right]_{2}$ [92] and Cu(II)-TETA [93], where the four amine nitrogen atoms of the ligands 1,4,8,11-tetrazazcyclotetradecane (CYCLAM) and 1,4,8,11-tetraazacyclotetradecane-1,4,8,11-tetraacetic acid (TETA) are encircled in a ring. In these complexes, the four nitrogen atoms achieve the preferred configuration (Fig. 7), because of their higher flexibility, and it has been shown that they are more stable than $\mathrm{Cu}$ (II)-DOTA in biological fluids [92,93].

A final example adding further evidence to the simple model discussed here, is obtained by considering the ligands CB-TE2A (1,4,8,11-tetra-azabicyclo[6.6.2] hexadecane-4,11-diacetic acid) [94,95] and $\mathrm{SARNH}_{2}$ [sarcophagine, 1,8-diamino3,6,10,13,16,19-hexaazabicyclo(6.6.6)eicosane] [96,97]. These chelating systems belong to a class of cross-bridged tetra- and hexamine macrobicyclic ligands (Fig. 4), and are pictured as bearing a kind of molecular cleft where the metal ion could be pocketed and, possibly, protected from transchelation. According to crystal data reported for the complex $\mathrm{Cu}$ (II)-CB-TE2A, the four nitrogen atoms do not achieve the most favorable square-planar arrangement. Conversely, the crystal structure of $\mathrm{Cu}(\mathrm{II})-\mathrm{SARNH}_{2}$ (Fig. 7) showed that four of the six nitrogen atoms attain almost completely the most stable square-planar arrangement around the metal. In agreement with the proposed interpretation, ${ }^{64} \mathrm{Cu}$-radiopharmaceuticals tethered to the CB-TE2A moiety were reported to be unstable in biological fluids, whereas the sarcophagine motif imparts high inertness to the corresponding complexes.

In summary, although some molecular architectures contribute to protect the copper ion from being captured by endogenous biomolecules, electronic factors do appear to have a primary role in kinetic stabilization. This is neatly demonstrated by the sharp increase in biological stability observed with ligands containing the $\mathrm{N}_{2} \mathrm{~S}_{2}$ chelating system $[77,78]$. Most importantly, when the nitrogen and sulfur atoms are linked by $\pi$-electron delocalization, as in bis-thiosemicarbazone ligands, the resulting coordination geometry is perfectly square planar (Fig. 6) and achieves the highest stabilization [98].

\section{Concluding remarks}

Research on ${ }^{64} \mathrm{Cu}$ is uncovering the tremendous impact on molecular imaging that might stem from the use of radioisotopes of elements that exhibit fundamental biological functions. When this key characteristic is also complemented by nuclear properties suitable for both diagnosis and therapy, it is reasonable to expect that this category of radioisotopes could become essential for theranostic applications. Previously, the only radioelement that demonstrated these characteristics was iodine-131. Although iodine radioisotopes offered the very first example of this type of radionuclide, the biological role of iodine is almost exclusively confined to thyroid tissues. By contrast, the copper element is essential for myriad cellular processes and, most importantly, is involved in some fundamental steps of cellular replication that also operate at the onset of a malignant transformation. Thus, imaging the in vivo biological behavior of copper ions with the corresponding, biologically equivalent, copper radioisotopes could provide an unprecedented opportunity to achieve the primary objective of molecular imaging. This suggests that copper radionuclides have enormous potential to promote the investigation of novel approaches for the detection and characterization of cancer at the deepest molecular level.

\section{References}

1 Weissleder, R.M. and Pittet, M.J. (2008) Imaging in the era of molecular oncology Nature 452, 580-589

2 Mottaghy, F.M. (2009) Current and future aspects of molecular imaging. Methods 48, $81-82$

3 Herschman, H.R. (2003) Molecular imaging: looking at problems, seeing solutions Science 302, 605-608

4 Ametamey, S.M. et al. (2008) Molecular imaging with PET. Chem. Rev. 108, 1501-1516

5 Sharma, S. (2016) PET Radiopharmaceuticals for personalized medicine. Curr. Drug. Targets 17, 1894-1907

6 Mankoff, D.A. (2007) A definition of molecular imaging. J. Nucl. Med. 48, 18N-21N

7 Duatti, A. (2015) Molecular imaging with endogenous and exogenous ligands: the instance of antibodies, peptides, iodide and cupric ions. Nucl. Med. Biol. 42, 215 218

8 Anon (2009) Cyclotron Produced Radionuclides: Physical Characteristics and Production Methods. International Atomic Energy Agency

9 Medvedev, D.G. et al. (2012) Development of a large scale production of ${ }^{67} \mathrm{Cu}$ from ${ }^{68} \mathrm{Zn}$ at the high energy proton accelerator: closing the ${ }^{68} \mathrm{Zn}$ cycle. Appl. Radiat. Isot. 70, 423-429

10 Guerra Gómez, F.L. et al. (2012) Production and purification of the positron emitter zinc-63. J. Label. Compd. Radiopharm. 55, 5-9

11 Fonslet, J. et al. (2017) Optimized procedures for manganese-52: production, separation and radiolabeling. Appl. Radiat. Isot. 121, 38-43

12 Rowshanfarzad, P. et al. (2006) An overview of copper radionuclides and production of ${ }^{61} \mathrm{Cu}$ by proton irradiation of ${ }^{\text {nat }} \mathrm{Zn}$ at a medical cyclotron. Appl. Radiat. Isot. 64, 1563-1573

13 Anon (2016) Cyclotron Produced Radionuclides: Emerging Positron Emitters for Medical Applications: ${ }^{64} \mathrm{Cu}$ and ${ }^{124}$ I. International Atomic Energy Agency

14 Svenson, S. (2013) Theranostics: are we there yet? Mol. Pharm. 10, 848-856

15 McCarthy, D.W. et al. (1997) Efficient production of high specific activity ${ }^{64}$ Cu using a biomedical cyclotron. Nucl. Med. Biol. 24, 35-43

16 Ohya, T. et al. (2016) Efficient preparation of high-quality ${ }^{64} \mathrm{Cu}$ for routine use. Nucl. Med. Biol. 43, 685-691

17 Thieme, S. et al. (2012) Module-assisted preparation of ${ }^{64} \mathrm{Cu}$ with high specific activity. Appl. Radiat. Isot. 70, 602-608

18 Xie, Q. et al. (2017) Establishing reliable Cu-64 production process: from target plating to molecular specific tumor micro-PET imaging. Molecules $22,1-10 \mathrm{http}: / / \mathrm{dx}$. doi.org/10.3390/molecules22040641

19 Manrique-Arias, J.C. and Avila-Rodriguez, M.A. (2014) A simple and efficient method of nickel electrodeposition for the cyclotron production of ${ }^{64} \mathrm{Cu}$. Appl. Radiat. Isot. 89, 37-41

20 Ometáková, J. et al. (2012) Automated production of ${ }^{64} \mathrm{Cu}$ prepared by $18 \mathrm{MeV}$ cyclotron. J. Radioanal. Nucl. Chem. 293, 217-222

21 Elomaa, V.V.et al. (2014) Automation of ${ }^{64} \mathrm{Cu}$ production at Turku PET Centre. Appl. Radiat. Isot. 89, 74-78 
22 Spahn, I. et al. (2004) Enhanced production possibility of the therapeutic radionuclides ${ }^{64} \mathrm{Cu},{ }^{67} \mathrm{Cu}$ and ${ }^{89} \mathrm{Sr}$ via $(n, p)$ reactions induced by fast spectral neutrons. Radiochim. Acta 92, 183-186

23 Mastren, T. et al. (2014) Feasibility of isotope harvesting at a projectile fragmentation facility: ${ }^{67} \mathrm{Cu}$. Sci. Rep. 4, 6706

24 Fukumura, T. et al. (2006) An improved ${ }^{62} \mathrm{Zn} /{ }^{62} \mathrm{Cu}$ generator based on a cation exchanger and its fully remote-controlled preparation for clinical use. Nucl. Med. Biol. 33, 821-827

25 McCarthy, D.W. et al. (1999) High purity production and potential applications of copper-60 and copper-61. Nucl. Med. Biol. 26, 351-358

26 Rubino, J.T. and Franz, K.J. (2012) Coordination chemistry of copper proteins: how nature handles a toxic cargo for essential function. J. Inorg. Biochem. 107, 129143

27 Kaplan, J.H. and Maryon, E.B. (2016) How mammalian cells acquire copper: an essential but potentially toxic metal. Biophys. J. 110, 7-13

28 Inesi, G. (2017) Molecular features of copper binding proteins involved in copper homeostasis. IUBMB Life 69, 211-217

29 Bharathi Devi, S.R. et al. (2016) Copper transporters and chaperones: their function on angiogenesis and cellular signalling. J. Biosci. 41, 487-496

30 Brady, D.C. et al. (2014) Copper is required for oncogenic BRAF signalling and tumorigenesis. Nature 509, 492-496

31 Ishida, S. et al. (2013) Bioavailable copper modulates oxidative phosphorylation and growth of tumors. Proc. Natl. Acad. Sci. U. S. A. 110, 19507-19512

32 Denoyer, D. (2015) Targeting copper in cancer therapy: 'Copper That Cancer'. Metallomics 7, 1459-1476

33 Fuchs, A.G. and de Lustig, E.S. (1989) Localization of tissue copper in mouse mammary tumors. Oncology 46, 183-187

34 Beaino, W. et al. (2014) Visualization of copper metabolism by ${ }^{64} \mathrm{CuCl}_{2}$-PET. J. Biol. Inorg. Chem. 19, 427-438

35 Peng, F. (2014) Positron emission tomography for measurement of copper fluxes in live organisms. Ann. N. Y. Acad. Sci. 1314, 24-31

36 Hueting, R. (2014) Radiocopper for the imaging of copper metabolism. J. Label. Comp. Radiopharm. 57, 231-238

37 Cai, H. et al. (2014) Reduced ${ }^{64} \mathrm{Cu}$ uptake and tumor growth inhibition by knockdown of human copper transporter 1 in xenograft mouse model of prostate cancer. J. Nucl. Med. 55, 622-628

$38 \mathrm{Kim}$, K.I. et al. (2014) Detection of increased ${ }^{64} \mathrm{Cu}$ uptake by human copper transporter 1 gene overexpression using PET with ${ }^{64} \mathrm{CuCl}_{2}$ in human breast cancer xenograft model. J. Nucl. Med. 55, 1692-1698

39 Jørgensen, J.T. et al. (2013) High tumor uptake of ${ }^{64} \mathrm{Cu}$ : implications for molecular imaging of tumor characteristics with copper-based PET tracers. Nucl. Med. Biol. 40 345-350

40 Chakravarty, R. et al. (2016) ${ }^{64} \mathrm{Cu}^{2+}$ ions as PET probe: an emerging paradigm in molecular imaging of cancer. Mol. Pharm. 13, 3601-3612

41 Evangelista, L. et al. (2013) New issues for copper-64: from precursor to innovative PET tracers in clinical oncology. Curr. Radiopharm. 6, 117-123

42 Qin, C. et al. (2014) Theranostics of malignant melanoma with ${ }^{64} \mathrm{CuCl}_{2}$. J. Nucl. Med. $55,812-817$

43 Asabella, N.A. et al. (2014) The Copper Radioisotopes: A Systematic Review with Special Interest to ${ }^{64} \mathrm{Cu}$. BioMed Res. Int. 2014, 1-9http://dx.doi.org/10.1155/2014/ 786463

44 Ferrari, C. et al. (2015) Copper-64 dichloride as theranostic agent for glioblastoma multiforme: a preclinical study. BioMed Res. Int. 2015, 1-6http://dx.doi.org/ $10.1155 / 2015 / 129764$

45 Safi, R. et al. (2014) Copper signaling axis as a target for prostate cancer therapeutics. Cancer Res. 74, 5819-5831

46 Zhang, H. et al. (2011) Positron emission tomography of human hepatocellular carcinoma xenografts in mice using copper (II)-64 chloride as a tracer with copper (II)-64 chloride. Acad. Radiol. 18, 1561-1568

47 Peng, F. et al. (2006) PET of human prostate cancer xenografts in mice with increased uptake of ${ }^{64} \mathrm{CuCl}_{2}$. J. Nucl. Med. 47, 1649-1652

48 Peng, F. et al. (2005) Mouse extrahepatic hepatoma detected on microPET using copper (II)-64 chloride uptake mediated by endogenous mouse copper transporter 1. Mol. Imaging Biol. 7, 325-329

49 Jiang, L. et al. (2017) Pilot study of ${ }^{64} \mathrm{Cu}(\mathrm{I})$ for PET imaging of melanoma. Sci. Rep. 7, 2574

50 Catalogna, G. et al. (2017) The SGK kinase inhibitor SI113 sensitizes theranostic effects of the ${ }^{64} \mathrm{CuCl}_{2}$ in human glioblastoma multiforme cell lines. Cell Physiol. Biochem. 43, 108-119

51 Capasso, E. et al. (2015) Role of ${ }^{64} \mathrm{CuCl}_{2}$ PET/CT in staging of prostate cancer. Ann. Nucl. Med. 29, 482-488

52 Piccardo, A. et al. (2018) ${ }^{64} \mathrm{CuCl}_{2}$ PET/CT in prostate cancer relapse. J. Nucl. Med 59, $444-451$
53 Panichelli, P. et al. (2016) Imaging of brain tumors with copper-64 chloride: early experience and results. Cancer Biother. Radiopharm. 31, 159-167

54 Wachsmann, J. and Peng, F. (2016) Molecular imaging and therapy targeting copper metabolism in hepatocellular carcinoma. World J. Gastroenterol. 22, 221-231

55 Kim, H. et al. (2009) Deletion of hepatic Ctr1 reveals its function in copper acquisition and compensatory mechanisms for copper homeostasis. Am. J. Physiol. Gastrointest. Liver Physiol. 296, G356-G364

56 Avila-Rodriguez, M.A. et al. (2017) Biodistribution and radiation dosimetry of ${ }^{64}$ Cucopper dichloride: first-in-human study in healthy volunteers. EJNMMI Res. 7, 98

57 Price, E.W. and Orvig, C. (2014) Matching chelators to radiometals for radiopharmaceuticals. Chem. Rev. 43, 260-290

58 Zeglis, B.M. and Lewis, J.S. (2011) A practical guide to the construction of radiometallated bioconjugates for positron emission tomograph. Dalton Trans. 40 6168-6195

59 Wadas, T.J. et al. (2010) Coordinating radiometals of copper, gallium, indium, yttrium, and zirconium for PET and SPECT imaging of disease. Chem. Rev. 110, 2858-2902

60 Anderson, C.J. et al. (2001) ${ }^{64} \mathrm{Cu}$-TETA-octreotide as a PET imaging agent for patients with neuroendocrine tumors. J. Nucl. Med. 42, 213-221

61 Pfeifer, A. et al. (2012) Clinical PET of neuroendocrine tumors using ${ }^{64} \mathrm{Cu}$ DOTATATE: first-in-humans study. J. Nucl. Med. 53, 207-1215

62 Pfeifer, A. et al. (2015) ${ }^{64} \mathrm{Cu}$-DOTATATE PET for neuroendocrine tumors: a prospective head-to-head comparison with ${ }^{111}$ In-DTPA-octreotide in 112 patients. J Nucl. Med. 56, 847-854

63 Johnbeck, C.B. et al. (2017) Head-to-head comparison of ${ }^{64} \mathrm{Cu}-\mathrm{DOTATATE}$ and ${ }^{68} \mathrm{Ga}$ DOTATOC PET/CT: a prospective study of 59 patients with neuroendocrine tumors. J. Nucl. Med. 58, 451-457

64 Cai, H. et al. (2010) An improved synthesis and biological evaluation of a new cagelike bifunctional chelator, 4-((8-amino-3,6,10,13,16,19-hexaazabicyclo[6.6.6] icosane-1-ylamino)methyl)benzoic acid, for ${ }^{64} \mathrm{Cu}$ radiopharmaceuticals. Nucl. Med Biol. 37, 57-65

65 Paterson, B.M. et al. (2014) PET imaging of tumours with a ${ }^{64} \mathrm{Cu}$ labeled macrobicyclic cage amine ligand tethered to Tyr3-octreotate. Dalton Trans. 43, 1386-1396

66 Gourni, E. and Henriksen, G. (2017) Metal-based PSMA ligands. Molecules 22, 134http://dx.doi.org/10.3390/molecules22040523

67 Grubmüller, B. et al. (2016) ${ }^{64} \mathrm{Cu}$-PSMA-617 PET/CT imaging of prostate adenocarcinoma: first in-human studies. Cancer Biother. Radiopharm. 31, 277-286

68 Singh, A. et al. (2017) Imaging of prostate cancer using ${ }^{64} \mathrm{Cu}$-labeled prostatespecific membrane antigen ligand. PET Clin. 12, 193-203

69 Cantiello, F. et al. (2017) Diagnostic accuracy of ${ }^{64}$ Copper prostate-specific membrane antigen positron emission tomography/computed tomography for primary lymph node staging of intermediate- to high-risk prostate cancer: our preliminary experience. Urology 106, 139-145

70 Persson, M. et al. (2015) First-in-human uPAR PET: imaging of cancer aggressiveness. Theranostics 5, 1303-1316

71 Kriegbaum, M.C. et al. (2011) Rational targeting of the urokinase receptor (uPAR): Development of antagonists and non-invasive imaging probes. Curr. Drug Targets $12,1711-1728$

72 Persson, M. et al. (2014) Dosimetry of ${ }^{64}$ Cu-DOTA-AE105, a PET tracer for uPAR imaging. Nucl. Med. Biol. 41, 290-295

73 Sasada, S. et al. (2017) Visualization of HER2-specific breast cancer intratumoral heterogeneity using ${ }^{64} \mathrm{Cu}-\mathrm{DOT}$ A-trastuzumab PET. Eur. J. Nucl. Med. Mol. Imaging 44, 2146-2147

74 Kurihara, H. et al. (2015) ${ }^{64}$ Cu-DOTA-trastuzumab PET imaging and HER2 specificity of brain metastases in HER2-positive breast cancer patients. EJNMMI Res. 5, 8

75 Sasada, S. et al. (2017) ${ }^{64}$ Cu-DOTA-trastuzumab PET imaging for HER2-specific primary lesions of breast cancer. Ann. Oncol. 8, 2028-2029

76 Thakur, M.L. et al. (2013) VPAC1 Receptors for imaging breast cancer: a feasibility study. J. Nucl. Med. 54, 1019-1025

77 Zahng, K. et al. (2008) PET Imaging of VPAC1 expression in experimental and spontaneous prostate cancer. J. Nucl. Med. 49, 112-121

78 Paterson, B.M. and Donnelly, P.S. (2011) Copper complexes of bis (thiosemicarbazones): from chemotherapeutics to diagnostic and therapeutic radiopharmaceuticals. Chem. Soc. Rev. 40, 3005-3018

79 Price, K.A. et al. (2011) Mechanisms controlling the cellular accumulation of copper bis(thiosemicarbazonato) complexes. Inorg. Chem. 50, 9594-9605

80 Colombié, M. et al. (2015) Focus on the controversial aspects of ${ }^{64} \mathrm{Cu}$-ATSM in tumoral hypoxia mapping by PET imaging. Front. Med. 2, 58

81 Hueting, R. et al. (2014) A comparison of the behavior of ${ }^{64} \mathrm{Cu}$-acetate and ${ }^{64} \mathrm{Cu}$ ATSM in vitro and in vivo. J. Nucl. Med. 55, 128-134 
82 Vāvere, A.L. and Lewis, J.S. (2007) Cu-ATSM: a radiopharmaceutical for the PET imaging of hypoxia. Dalton Trans. 4893-4902

83 Maheshwari, V. et al. (2012) Measurement of the rate of copper(II) exchange for ${ }^{64} \mathrm{Cu}$ complexes of bifunctional chelators. Inorg. Chim. Acta 393, 318-323

84 Cai, Z. and Anderson, C.J. (2014) Chelators for copper radionuclides in positron emission tomography radiopharmaceuticals. J. Label. Compd. Radiopharm. 57, 224 230

85 Shokeen, M. and Wadas, T.J. (2011) The development of copper radiopharmaceuticals for imaging and therapy. Med. Chem. 7, 413-429

86 Stasiuk, G.J. and Long, N.J. (2013) The ubiquitous DOTA and its derivatives: the impact of 1,4,7,10-tetraazacyclododecane-1,4,7,10-tetraacetic acid on biomedical imaging. Chem. Commun. 49, 2732-2746

87 Viola-Villegas, N. and Doyle, R.P. (2009) The coordination chemistry of $1,4,7,10$ tetraazacyclododecane- $\mathrm{N}, \mathrm{N}^{\prime}, \mathrm{N}^{\prime \prime}, \mathrm{N}^{\prime \prime \prime}$-tetraacetic acid (H4DOTA): structural overview and analyses on structure-stability relationships. Coord. Chem. Rev. 253, 1906-1925

88 Kumar, K. et al. (1995) Synthesis, stability, and crystal structure studies of some $\mathrm{Ca}^{2}$ ${ }^{+}, \mathrm{Cu}^{2+}$, and $\mathrm{Zn}^{2+}$ complexes of macrocyclic polyamino carboxylates. Inorg. Chem. 34, 6472-6480

89 Riesen, A. et al. (1988) Structure of the barium salt of a $\mathrm{Cu}^{2+}$ complex with a tetraaza macrocyclic tetraacetate. Acta Crystallogr. C Cryst. Struct. Commun. C44, 1740-1742

90 Morosin, B. (1969) The crystal structures of copper tetrammine complexes. A. Cu $\left(\mathrm{NH}_{3}\right)_{4} \mathrm{SO}_{2} \cdot \mathrm{H}_{2} \mathrm{O}$ and $\mathrm{Cu}\left(\mathrm{NH}_{3}\right)_{4} \mathrm{SeO}_{4}$. Acta Cryst. B25, 19-30
91 Kovbasyuk, L.A. et al. (1997) Synthesis and structure of diaqua-bis (ethylenediamine)copper(II) salts with anions of carbamic acids. Polyhedron 16, 1723-1729

92 Delgado, R. et al. (2007) Metal complexes of cyclen and cyclam derivatives useful for medical applications: a discussion based on thermodynamic stability constants and structural data. Dalton Trans. 2734-2745

93 Silversides, J.D. et al. (2007) Copper(II) cyclam-based complexes for radiopharmaceutical applications: synthesis and structural analysis. Dalton Trans. 971-978

94 Wong, E.H. et al. (2000) Synthesis and characterization of cross-bridged cyclams and pendant-armed derivatives and structural studies of their copper(II) complexes. $J$. Am. Chem. Soc. 122, 10561-10572

95 Hubin, T.J. et al. (1998) Ultra rigid cross-bridged tetraazamacrocycles as ligands: the challenge and the solution. Chem. Commun. 1675-1676

96 Bernhardt, P.V. et al. (1995) Copper(II) complexes of substituted macrobicyclic hexaamines: combined trigonal and tetragonal distortions. Inorg. Chem. 34, 3589 3599

97 Di Bartolo, N.M. et al. (2001) Synthesis of a new cage ligand, SarAr, and its complexation with selected transition metal ions for potential use in radioimaging. J. Chem. Soc. Dalton Trans. 2303-2309

98 Blower, P.J. (2003) Structural trends in copper(II) bis(thiosemicarbazone) radiopharmaceuticals. Dalton Trans. 4416-4425 